\title{
Oviposition behavior and progeny production of Trichogramma evanescens (Hymenoptera: Trichogrammatidae) in patches of single and clustered host eggs
}

\author{
Sayed A. Ahmed
}

Faculty of Environmental Agricultural Sciences, Suez Canal University, El-Arish, Egypt

\begin{abstract}
The oviposition behavior of $T$. evanescens in each patch type $\left(1 \mathrm{~mm}^{2}\right)$ with 12 single spaced or clustered eggs of Anagasta kuehniella Zeller was observed continuously, recorded and calculated the patterns of patch use, time budgets, and the sequence of sex allocation for up to $1 \mathrm{hr}$. or until the female left the patch. The only significant behavioral event is the total walking in cluster patch because the female takes significantly more time walking out of patch. The parasitoid spends much time resting on eggs of cluster patch than in single patch. No significant differences occurred between single and cluster patches in their influence on the residence time spent in a patch. The handling time in a patch showed significant differences between single and cluster patch. There is no giving up time in single patch but it happened in cluster patch. Clustered patches led to a reduction in percent drumming and grooming time, but an increase in percent resting and total walking time. There were no significant differences between single and cluster patches in the number of eggs encountered. The progeny sex ratio from the parasitized eggs showed very little variation and was insignificant between patch types. The percent male progeny was 16.1 and $21.2 \%$ in single and cluster patches, respectively. There were no significant differences for oviposition time for both male or female eggs in single and cluster patches. The female tended to produce male eggs at the second oviposition event in single patch which represented $16.67 \%$ of the total male eggs deposited, while it deposited male eggs $(8.7 \%)$ at the first oviposition event. This study has important implications for Trichogramma inundation programs and selecting Trichogramma species and strains, it should be taken into consideration to match the behavioral and reproductive characteristics of Trichogramma species to the ovipositional strategies (single eggs versus egg masses) of target pests.
\end{abstract}

Keywords: Trichogramma evanescens - Biological control

\section{INTRODUCTION}

The analysis of the important process of ovipositional behaviour and distribution of progeny must be done keeping in mind that it has various modalities depending upon the manner by which the parasitoid's progeny reaches the host. Following are few examples of those modalities. All species of Trichogramma of which the biology is known are endoparasitoids of eggs of various groups of insects, mainly Lepidoptera. The hosts are sessile, making it possible for the female to examine the host at her leisure before depositing her egg. This characteristic is common to all egg parasitoids, such as other Trichogrammatidae, Mymaridae, Scelionidae, some Eulophidae and Encyrtidae.

Trichogramma egg parasitoids have been widely used in augmentative biological control of a variety of agricultural and forest pests in many regions of the world (Li, 1994; Smith, 1996). They are gregarious endoparasitoids and broadly 
polyphagous attacking host eggs from a wide range of families within the Lepidoptera (Pinto, 1998).

Quality control has frequently been suggested to be of overriding importance in the success of inundative biological control (Hoy et al., 1991; Obrycki et al., 1997; Parrella et al., 1992), particularly for Trichogramma releases (Bigler, 1994; Hassan and Zhang, 2001; Liu and Smith, 2000). The original concept of inundation was to overcome any limitations of the control agent or the environment into which it is released through mass release (DeBach, 1964). It has become clear that a greater knowledge of the ecology and behavior of the natural enemy is often essential in the development of inundative control programs (Daane, 2001; Luck and Forster, 2003; Obrycki et al., 1997). Some of lepidopteran insects lay their eggs singly on their hosts, whereas others lay eggs in large clusters. These differences in egg distribution and abundance present very different targets for Trichogramma parasitism.

The aim of this study is to get information on the sequence of behavioral events and progeny production exhibited by individual females of $T$. evanscences in a simple laboratory arena when presented with eggs of a single host species arrayed either singly or in tight clusters in a patch. The parasitoids were observed continuously to estimate all behavioral events, patterns of patch use, time budgets for behavioral events, and the sequence of allocation of male and female eggs within a patch.

\section{MATERIALS AND METHODS}

\section{Parasitoids and host eggs}

The parasitoid used in this study was $T$. evanescens. It was obtained from a laboratory colony (Trichogramma Project) at Directorate of Agriculture in North Sinai governorate, maintained on eggs of Sitotroga cerealella (Olivier) (Lepidoptera, Gelechiidae).To isolate females for these experiments, small squares from the egg card were placed into emergence canisters held in incubators at $25 \pm 1^{\circ} \mathrm{C}$. Once the parasitoids had emerged into a glass vial, it was removed, provisioned with undiluted honey as a food source, and closed with a ventilated plastic cap to serve as a holding container until females were $24 \mathrm{~h}$ old. Immediately before being used for behavioral observation individual females were given access to a small egg card with eggs of Anagasta kuehniella Zeller (Lepidoptera: Pyralidae) for $10 \mathrm{~min}$ to gain oviposition experience. Females were given initial experience to avoid the variability in sequence and duration of behavioral events associated with learning from the first eggs encountered (Wajnberg, 1989).

Eggs of A. kuehniella were used for all observations for both single and clustered patches. Eggs were obtained from a culture maintained at the Insectary of Entomology Laboratory, Faculty of Environmental Agricultural Sciences, Suez Canal University. The culture was reared at $25 \pm 1^{\circ} \mathrm{C}$ on wheat flour. Mated female moths were kept in glass containers for the production of eggs. Eggs were collected daily to ensure that the live eggs used in the experiments were not less or more than $24 \mathrm{~h}$ old.

\section{Experimental design}

All experiments were carried out in a room controlled at a temperature of $25 \pm$ $1{ }^{\circ} \mathrm{C}$. The ovipositional behavior of individual Trichogramma females was monitored continuously under a dissecting microscope and recorded with a video cameraon a desk top computer. Designated sheets of paper were used to keep track of multiple encounters and ovipositions on each host egg.

Individual Trichogramma females were presented with egg patches consisting of 12 host eggs glued with water as a patch onto 10x10 cardboard squares; each 
square $1 \mathrm{~mm}$. For a singly spaced patch, the host eggs were arranged in a $8 \mathrm{x} 5$ squares, and the distance between eggs was $1 \mathrm{~mm}$ and one row contains squares each $1 \mathrm{~mm}$ were left between rows in one of two arrangements. The eggs in a patch were individually numbered from 1 to 12 . For a tightly clustered patch, eggs were arranged in contact with each other in a $4 \times 3$ squares at the center of the patch. After a series of preliminary observations of the ovipositional behavior of Trichogramma females, the following set of parameters and behavioral events were defined: A sequence of seven behavioral events was recorded, six of them (Walking, Drumming, Drilling, Oviposition, Host feeding and Resting) were mentioned in other species (Blanche et al., 1996 and Mills and Kuhlmann 2004) and the last one event behaviour; grooming was added in this study: i.e., 1- Walking (walking in patch and walking out of patch) 2- Drumming (host examination) 3- Drilling (drilling before oviposition and drilling after oviposition) 4- Oviposition 5- Grooming (cleaning itself) 6- Host feeding 7- Resting

After $10 \mathrm{~min}$ of experience with host eggs, an individual Trichogramma female was held for $5 \mathrm{~min}$ in a glass vial before gently being released onto a cardboard patch. Each observation period started at the moment when the female touch any egg of the patch. An observation was terminated after 3600 second or when the parasitoid left the cardboard patch. Ten Trichogramma females were used to record all observations for each patch type. The parasitized egg patch from each observation period was incubated at $25 \pm 1{ }^{\circ} \mathrm{C}$ for $4-5$ days before being checked for successful parasitism, detected visually from the black coloration of host eggs produced at parasitoid pupation. Parasitized host eggs were gently removed of the cardboard patch by using a fine brush and placed individually in small capsules to await emergence of the parasitoid progeny. The sex of the emerging parasitoids was determined from morphological differentiation of the antennae.

\section{Data analysis}

The recorded events for each female were treated separately. In addition to the individual behavioral events noted above, the following patch use measurements were noted for each female:

A- Patch handling time. The total time spent for drumming, drilling, ovipositing, host feeding or resting the host eggs

B- Patch residence time. The time between the first encounter of a host egg and the female parasitoid leaving the patch (terminated at 3600 seconds).

Patch residence time $=$ patch handling time + the total walking time between eggsthe total time which the female left the patch and came back to patch.

C- Giving up time. The time between the last oviposition event and the female leaving the patch.

Data were analyzed by the use of SPSS version 13 software for getting the total mean and standard error, also F value and LSD were obtained.

\section{RESULTS AND DISCUSSION}

\section{Qualitative analysis of oviposition behaviour:}

\section{A. Sequence of ovipositional behavior.}

In general, a parasitoid started by walking to an egg, drumming over the surface of the chorion, drilling through the chorion, ovipositing into the egg, and then walking between eggs or walking out of patch and come back to patch to start drumming another egg. Although grooming, host feeding and resting as an events were recorded during the complete 60 -min observation periods. Grooming, host 
feeding and Resting were generally infrequent (Table 1).

The general sequence of the ovipositional behavior events of $T$. evanescens was similar to that found for Trichogramma platneri and Trichogramma pretiosum by Mills and Kuhlmann (2004) and T. brassicae by Blanche et al. (1996) and for Trichogramma australicum by Nurindah et al. (1999). T. australicum differs from these species in that it tends to drill an egg again before host feeding following an oviposition. T. platneri and T. pretiosum differ from the other species, the females reject hosts after drumming (host examination), but before drilling. For T. evanescens, host feeding occurred on approximately at eighth egg encountered of egg distribution(clustered eggs), whereas, host feeding occurred on approximately at eleventh egg encountered of egg distribution (single eggs) .It is interesting to note that there is considerable variation in the incidence of host feeding among these Trichogramma species.

The host feeding is not uncommon amongst Trichogramma species; its significance is poorly understood. Host feeding is unlikely to provide resources for egg production and, in general, sugar sources tend to be more efficiently used than host fluids for somatic maintenance (Rivero and Casas, 1999). One possible explanation is that host feeding by Trichogramma parasitoids may serve merely to replenish water supplies rather than nutrients. In two patch types, host feeding was non-destructive. The resting event took a long time in this case of cluster patch, while it rested occasionally and took a short time; in case of single patch.

Table (1). Total mean time budget / seconds for Trichogramma evanescens searching a patch containing 12 A. kuehniella eggs spaced either singly or in a tight cluster

\begin{tabular}{ll|l}
\hline Parameters of behavioural events & Single & Cluster \\
\cline { 2 - 3 } & Mean \pm SE & Mean \pm SE \\
\hline Total walking & $383.2 \pm 36.88 \mathrm{a}$ & $711.5 \pm 105.69 \mathrm{~b}$ \\
A- Walking in patch & $294.4 \pm 27.66 \mathrm{a}$ & $415.10 \pm 51.82 \mathrm{a}$ \\
B- Walking out of patch & $88.80 \pm 20.40 \mathrm{a}$ & $296.40 \pm 102.01 \mathrm{a}$ \\
Drumming & $79.86 \pm 4.01 \mathrm{a}$ & $67.60 \pm 3.06 \mathrm{a}$ \\
Total drilling & $120.99 \pm 6.05 \mathrm{a}$ & $107.48 \pm 5.50 \mathrm{a}$ \\
A- Drilling before ovipositing & $49.68 \pm 2.87 \mathrm{a}$ & $48.16 \pm 1.18 \mathrm{a}$ \\
B- Drilling after ovipositing & $71.31 \pm 5.49 \mathrm{a}$ & $59.32 \pm 5.14 \mathrm{a}$ \\
Ovipositing & $53.51 \pm 2.75 \mathrm{a}$ & $44.59 \pm 2.20 \mathrm{a}$ \\
Host feeding & $64.50 \pm 21.37 \mathrm{a}$ & $79.20 \pm 18.27 \mathrm{a}$ \\
Grooming & $17.80 \pm 12.54 \mathrm{a}$ & $4.90 \pm 2.29 \mathrm{a}$ \\
Resting & $12.90 \pm 7.07 \mathrm{a}$ & $46.70 \pm 28.97 \mathrm{a}$ \\
Superparasitism & $5.13 \pm 1.92 \mathrm{a}$ & $3.64 \pm 1.15 \mathrm{a}$ \\
\hline
\end{tabular}

Means followed by different lower case letters are significantly different between patches at $\mathrm{P}<0: 05$.

\section{Quantitative analysis of oviposition behaviour:}

\section{A. Time budget for behavioral events}

From the relative time budgets (Table 1), represented by the total mean time in a patch allocated to each of the behavioral events, events rank from greatest to least time expenditure as walking in patch, walking out of patch, drumming, drilling after oviposition, host feeding, oviposition, drilling before oviposition, grooming, resting in single patch, while it was walking in patch, walking out of patch, host feeding, drumming, drilling after oviposition, drilling before oviposition, resting, oviposition, grooming in cluster patch. The only behavioral event with a significant is the total walking in cluster patch $(711.5 \pm 105.69 \mathrm{sec}$.) due to $T$. evanescens spending 
significantly more time walking out of patch in clustered patch $(415.10 \pm 51.82$ sec.), while less time was spent walking out of patch in single patch. The parasitoid spends much time resting on eggs in cluster patch $(46.70 \pm 28.97 \mathrm{sec}$.) than in single patch $(12.90 \pm 7.07 \mathrm{sec}$. $)$.

The parasitoid females re-encountered eggs that had already been parasitized were 7 of 10 eggs in single patch, while it was 5 of 10 in cluster patch (Table 2) and the total mean time spent in superparasitized one egg ranged between 5.13 and 3.64 sec. (Table 1).

\section{B. Patterns of patch use}

Data in Table (2) showed insignificant differences between two patch types (single and cluster) in their influence on the residence time spent in a patch, $3472.80 \pm 26.58$ and $3126.50 \pm 147.296$ sec., respectively with spending substantially less time using a clustered egg patch. The handling time in a patch showed significant differences between the two patch types $3178.40 \pm 35.26$ and $2711.40 \pm 154.51 \mathrm{sec}$., respectively. For giving up time, data showed that there is no giving up time in single patch but it was $124.9 \pm 68.68 \mathrm{sec}$. in cluster patch. Patch type had no influence on the number of females that superparasitized one or more eggs, the time until the first superparasitism occurred, patch handling time or patch sex ratio, patch type had less influence on the relative time budget of the two patch types Mills and Kuhlmann (2004). Clustered patches led to a reduction in percent drumming and grooming time, but an increase in percent resting and total walking time.

Table (2) Patterns of patch use by Trichogramma evanesces searching a patch containing $12 \mathrm{~A}$ kuehniella eggs spaced either singly or in a tight cluster

\begin{tabular}{lll}
\hline Pattern of patch and progeny production & Single & Cluster \\
\cline { 2 - 3 } & Mean \pm SE & Mean \pm SE \\
\hline Patch residence time (s) & $3472.80 \pm 26.58 \mathrm{a}$ & $3126.50 \pm 147.296 \mathrm{a}$ \\
Patch handling time (s) & $3178.40 \pm 35.26 \mathrm{a}$ & $2711.40 \pm 154.51 \mathrm{~b}$ \\
Giving up time (s) & $0.00 \pm 0.00$ & $124.9 \pm 68.68$ \\
Eggs encountered & $11.6 \pm 0.16 \mathrm{a}$ & $11.9 \pm 0.1 \mathrm{a}$ \\
Ovipositions per female & $11.2 \pm 0.2 \mathrm{a}$ & $11.3 \pm 0.26 \mathrm{a}$ \\
Females that superparasitized eggs (total females) & $7(10)$ & $5(10)$ \\
Patch sex ratio (\% males) & $16.1 \mathrm{a}$ & $21.2 \mathrm{a}$ \\
Oviposition time (s) & & \\
$\quad$ for a female egg & $70.64 \pm 15.88 \mathrm{a}$ & $108.25 \pm 41.90 \mathrm{a}$ \\
$\quad$ for a male egg & $61.75 \pm 12.61 \mathrm{a}$ & $49.8 \pm 15.03 \mathrm{a}$ \\
\hline
\end{tabular}

Means followed by different lower case letters are significantly different between patches at $\mathrm{P}<0: 05$.

There were no significant differences between the two patch types in the number of eggs encountered in a patch being11.6 \pm 0.16 and $11.9 \pm 0.1$ eggs, respectively. Also, no significant differences for the number of ovipositions per female for both two patch types recording $11.2 \pm 0.2$ and $11.3 \pm 0.26$, respectively.

The progeny sex ratio from the parasitized eggs showed very little variation and was insignificant between patch types. The percent male progeny was 16.1 and $21.2 \%$ in single and cluster patches, respectively. There were no significant differences for oviposition time for either male or female eggs in single and cluster patches where they recorded $70.64 \pm 15.88,108.25 \pm 41.90$ and $61.75 \pm 12.61,49.8$ $\pm 15.03 \mathrm{sec}$., respectively.

For patch with single eggs, T. evanescens tended to produce male eggs at the second oviposition event which represented $16.67 \%$ of the total male eggs deposited, and the majority of male eggs deposited between the sixth and twelfth male eggs 
represented $50 \%$ of the total male eggs deposited. For patch with clustered eggs, females were deposited male eggs at the first oviposition event representing $8.7 \%$, while it was $73.9 \%$ for the male eggs deposited between the sixth and twelfth male eggs. Haplodiploid parasitoids have the ability to manipulate offspring sex ratios according to environmental conditions by controlling fertilization of eggs (Godfray, 1994). When hosts are tightly clustered, local mate competition between offspring leads to the production of female-biased sex ratios (Hardy, 1994). For many parasitoids, including Trichogramma species, precise sex ratios are achieved by male and female eggs being laid in a more or less fixed sequence, with a greater likelihood that male eggs are laid early in the oviposition sequence (Chow and Mackauer, 1996; Noda and Hirose, 1989; Suzuki et al., 1984; Waage and Ng, 1984; Wajnberg, 1993).

This study has important implications for Trichogramma inundation programs. Also, for selecting Trichogramma species and strains (Hassan, 1989; McGregor et al., 1998; Tabone et al., 1999), attention should be paid to matching the behavioral and reproductive characteristics of Trichogramma species to the ovipositional strategies (single eggs versus egg masses) of target pests.

\section{REFERENCES}

Bigler, F. (1994). Quality control in Trichogramma production. In: Wajnberg, E., Hassan, S. A. (Eds.), Biological Control with Egg Parasitoids. CAB International, Wallingford, UK, pp. 93-112.

Blanche, S.; Casas, J.; Bigler, F. and Janssen-Van Bergeijk, K. E. (1996). An individual-based model of Trichogramma foraging behaviour: parameter estimation for single females. J. Appl. Ecol. 33: 425-434.

Chow, A. and Mackauer, M. (1996). Sequential allocation of offspring sexes in the hyperparasitoid wasp, Dendrocerus carpenteri. Anim. Behav. 51: 859-870.

Daane, K. M. (2001). Ecological studies of released lacewings in crops. In: McEwen, P., New, T. R., Whittington, A. E. (Eds.), Lacewings in the Crop Environment. Cambridge University Press, Cambridge, UK, pp.338-350.

DeBach, P. (1964). Biological Control of Insect Pests and Weeds. Chapman \& Hall, London.

Godfray, H. J. C. (1994). Parasitoids. Behavioral and Evolutionary Ecology. Princeton University Press, Princeton, N J.

Hardy, I.C.W. (1994). Sex ratio and mating structure in the parasitoid Hymenoptera. Oikos 69: 3-20.

Hassan, S. A. (1989). Selection of suitable Trichogramma strains to control the codling moth Cydia pomonella and the two summer fruit tortrix moths Adoxophyes orana, Pandemis heparana (Lep. : Tortricidae). Entom.,34:19-27.

Hassan, S. A. and Zhang, W. Q. (2001). Variability in quality of Trichogramma brassicae (Hymenoptera: Trichogrammatidae) from commercial suppliers in Germany. Biol. Control 22: 115-121.

Hoy, M. A.; Nowierski, R. M.; Johnson, M. W. and Flexner, J. L. (1991). Issues and ethics in commercial releases of arthropod natural enemies. Am. Entomol., 37: 74-75.

Li, L.Y. (1994). Worldwide use of Trichogramma for biological control on different crops: a survey. In: Wajnberg, E., Hassan, S. A. (Eds.), Biological Control with Egg Parasitoids. CAB International, Wallingford, UK, pp. 37-54. 
Liu, F. and Smith, S. M. (2000). Measurement and selection of parasitoid quality for mass-reared Trichogramma minutum Riley used in inundative release. Biocontrol Sci. Technol., 10:3-13.

Luck, R. F. and Forster, L. D. (2003). Quality of augmentative biological control agents: a historical perspective and lessons learned from evaluating Trichogramma. In: van Lenteren, J. C. (Ed.), Quality Control and Production of Biological Control Agents: Theory and Testing Procedures. CABI Publishing, Wallingford, UK, pp. 231-246.

McGregor, R.; Hueppelsheuser, T.; Luczynski, A. and Henderson, D. (1998). Collection and evaluation of Trichogramma species (Hymenoptera: Trichogrammatidae) as biological controls of the oblique-banded leafroller Choristoneura rosaceana (Harris) (Lepidoptera: Tortricidae) in raspberries and blueberries. Biol. Control 11: 38-42.

Mills, N. J. and Kuhlmann, U. (2004). Oviposition behavior of Trichogramma platneri Nagarkatti and Trichogramma pretiosum Riley (Hymenoptera: Trichogrammatidae) in patches of single and clustered host eggs Biological Control, 30: 42-51

Noda, T. and Hirose, Y. (1989). 'Males second' strategy in the allocation of sexes by the parasitic wasp, Gryonjaponicum. Oecologia 81:145-148.

Nurindah, Cribb B. W. and Gordh, G. (1999). Effects of physiological condition and experience on oviposition behaviour of Trichogramma australicum Girault (Hymenoptera: Trichogrammatidae) on eggs of Helicoverpa armigera Hubner (Lepidoptera: Noctuidae). Austral. J. Entomol., 38:104-114.

Obrycki, J. J.; Lewis, L. C. and Orr, D. B. (1997). Augmentative releases of entomophagous species in annual cropping systems. Biol. Control, 10: 30-36.

Parrella, M. P.; Heinz, K. M. and Nunney, L. (1992). Biological control through augmentative release of natural enemies: a strategy whose time has come. Am. Entomol., 38: 172-179.

Pinto, J. D. (1998). Systematics of the North American species of Trichogramma Westwood (Hymenoptera: Trichogrammatidae). Mem. Entomol. Soc. Wash. 22: 1-287.

Rivero, A. and Casas, J. (1999). Incorporating physiology into parasitoid behavioral ecology: the allocation of nutritional resources. Res. Popul. Ecol. 41: 39-45.

Smith, S. M. (1996). Biological control with Trichogramma: advances, successes, and potential for their use. Annu. Rev. Entomol. 41: 375-406.

Suzuki, Y.; Tsuji, H. and Sasakawa, M. (1984). Sex allocation and effects of superparasitism on secondary sex ratios in the gregarious parasitoid, Trichogramma chilonis (Hymenoptera: Trichogrammatidae). Anim. Behav. 32: 478-484.

Tabone, E.; Pintureau, B.; Pizzol, J.; Michel, F. and Barnay, O. (1999). Ability of 17 strains of Trichogramma to control Plutella xylostella L. (Lep.: Yponomeutidae), in the laboratory. Ann. Soc. Entomol. Fr. 35: 427-433.

Waage, J. K. and Ng, S. M. (1984). The reproductive strategy of a parasitic wasp. I. Optimal progeny and sex allocation in Trichogramma evanescens. J. Anim. Ecol. 53: 401-415.

Wajnberg, E. (1989). Analysis of variations in handling time in Trichogramma maidis. Entomophaga 34: 397- 408.

Wajnberg, E. (1993). Genetic variation in sex allocation in a parasitic wasp: variation in sex pattern within sequences of oviposition. Entomol. Exp. Appl., 69: 221229. 


\title{
ARABIC SUMMARY
}

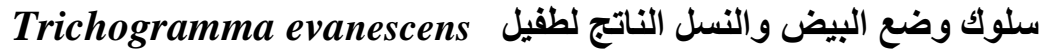 فى نظام البيض الفردي والمتجمع لبيض العائل.}

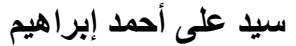 \\ كلية العلوم الزراعية البيئية بالعريش- جامعة قناة السويس
}

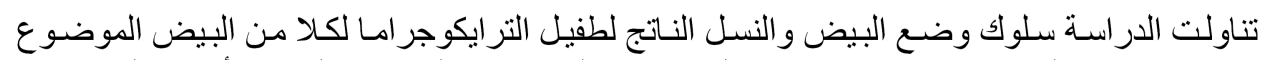

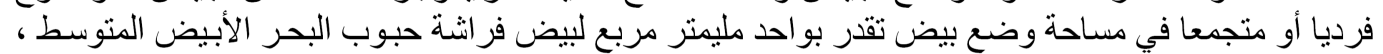

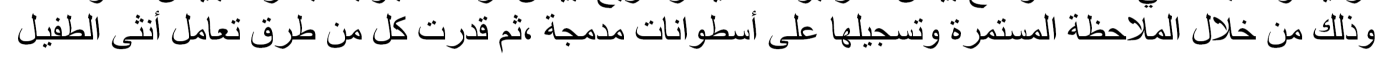

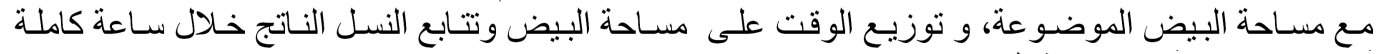

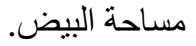

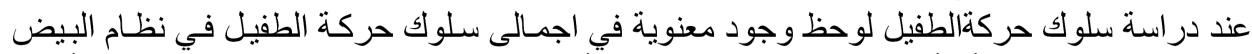

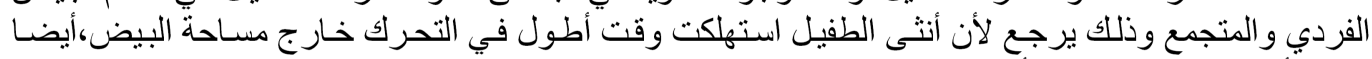

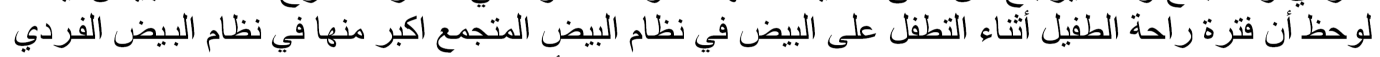

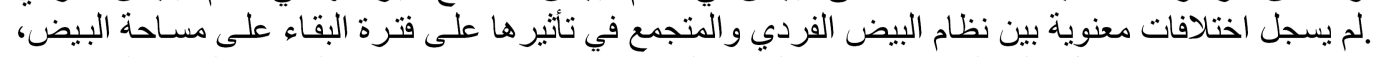

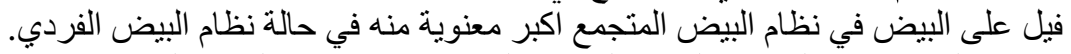
يحدث أن ترك الطفيل مساحة البيض في حالة نظام البيض الفردي ولكنه حدث في نظام البيض التئنمع.

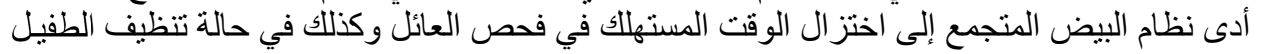

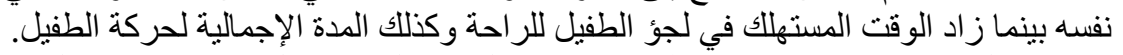

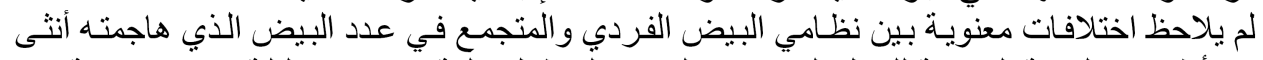

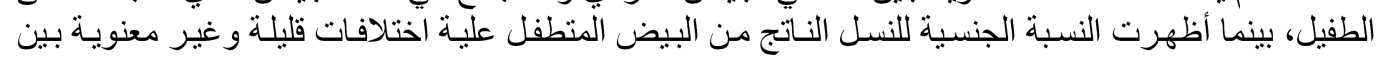

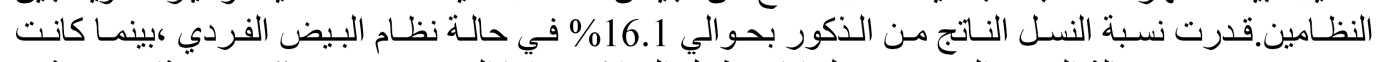

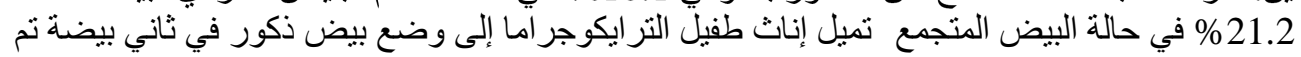

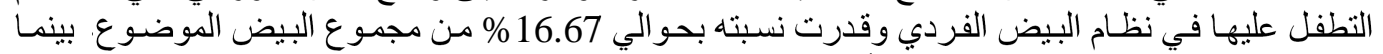

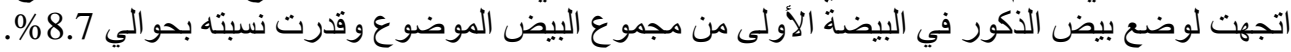

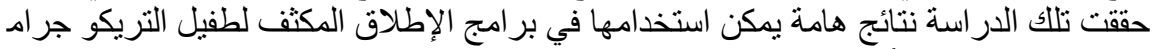

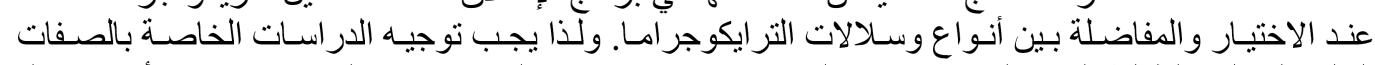

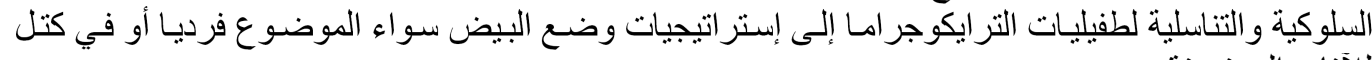

